\title{
Produtividade de biomassa e composição bromatológica de genótipos de aveia forrageira em Vitória da Conquista, BA
}

\author{
Biomass productivity and bromatological composition of forage oat genotypes in Vitória da \\ Conquista, BA
}

\author{
G. L. P. Moreira'; E. de S. Moreira'; C. J. N. Prates ${ }^{1 *}$; N. dos S. Cardoso Júnior ${ }^{2}$; \\ A. E. S. Viana ${ }^{2}$; S. C. Lopes ${ }^{2}$ \\ ${ }^{1}$ Programa de Pós-graduação em Agronomia - Fitotecnia, Universidade Estadual do Sudoeste da Bahia, 45031-900, \\ Vitória da Conquista,Bahia, Brasil \\ ${ }^{2}$ Departamento de Fitotecnia e Zootecnia/Laboratório de Melhoramento e Produção Vegetal, Universidade Estadual \\ do Sudoeste da Bahia, 45083-900,Vitória da Conquista, Bahia, Brasil \\ *caiojander@hotmail.com
}

(Recebido em 14 de novembro de 2016; aceito em 20 de março de 2017)

\begin{abstract}
O presente trabalho foi conduzido com o objetivo de avaliar e selecionar genótipos de aveia forrageira adaptados às condições edafoclimáticas de Vitória da Conquista, município localizado em região tropical de altitude no estado da Bahia. Utilizou-se o delineamento experimental em blocos casualizados, com três repetições e nove tratamentos, constituídos pelos genótipos São Carlos, UPF 86081, FAPA 2, FAPA 43, UPF 15, IAPAR 61, UPF 19, IPR 126, UFRGS 16. A semeadura foi realizada manualmente, após aração e gradagem do solo, em maio de 2006. A adubação nitrogenada variou de 80 a $120 \mathrm{~kg} \mathrm{ha}^{-1}$ de $\mathrm{N}$, divididos em aplicações no momento do plantio, 20 dias após o plantio e após cada corte. Nos períodos de baixa disponibilidade hídrica foi utilizada irrigação suplementar via aspersão. O primeiro corte foi realizado no início de emborrachamento e os cortes seguintes, quando as plantas atingiram altura entre 35 e $40 \mathrm{~cm}$. Foram avaliados o número de dias da emergência ao florescimento e o número de dias da emergência ao amadurecimento dos grãos para determinação do ciclo de crescimento dos genótipos. Ao longo do ensaio, foram avaliadas as produtividades de massa verde e massa seca e a composição bromatológica, determinando-se os teores de proteína bruta, fibra em detergente neutro, fibra em detergente ácido e digestibilidade in vitro da matéria seca. Os genótipos UPF 86081, UPF 19 e UFRGS 16 apresentaram potencial de utilização na região, no período de inverno, com maior produtividade de biomassa verde, enquanto que os genótipos FAPA 43, FAPA 2, IPR 126, IAPAR 61, UPF 15 e São Carlos apresentam melhor desempenho bromatológico com reduzido conteúdo de fibras e maior digestibilidade da matéria seca.
\end{abstract}

Palavras-chave: Avena spp, qualidade nutricional, produtividade de forragem

The present study was conducted with the objective of evaluating and selecting forage oat genotypes adapted to the edaphoclimatic conditions of Vitória da Conquista, municipality located in a tropical region of altitude in the state of Bahia. It was used the experimental design in randomized blocks, with three replicates and nine treatments, constituted by the genotypes São Carlos, UPF 86081, FAPA 2, FAPA 43, UPF 15, IAPAR 61, UPF 19, IPR 126, UFRGS 16. The seeding was performed manually, after plowing and soil harrowing, in May 2006. The nitrogen fertilization varied from 80 to $120 \mathrm{~kg} \mathrm{ha}^{-1}$ of $\mathrm{N}$, divided in applications at the time of planting, 20 days after planting and after each cut. In periods of low water availability was used additional irrigation via sprinkling. The first cut was performed at the beginning of rubber and the following cuts, when the plants reached height between 35 and $40 \mathrm{~cm}$. Were evaluated the number of days from emergence to flowering and the number of days of emergence to maturing of the grains to determine the growth cycle of the genotypes. Throughout the essay, were evaluated the green mass production and dry mass and the bromatological composition, determining the levels of crude protein, neutral detergent fiber, acid detergent fiber and in vitro digestibility of the dry matter. The genotypes UPF 86081, UPF 19 and UFRGS 16 presented potential of use in the region, in the winter period, with higher productivity of green biomass, while the genotypes FAPA 43, FAPA 2, IPR 126, IAPAR 61, UPF 15 and São Carlos show better bromatological performance with reduced fiber content and higher dry matter digestibility.

Keywords:Avena spp., nutritional quality, forage yield 


\section{INTRODUÇÃO}

A pecuária brasileira caracteriza-se por sistemas de produção quase que exclusivamente extensivos [10], utilizando plantas forrageiras no pastejo direto ou fornecidas no cocho, na forma de silagem, feno ou como ingredientes para formulação de rações. Todavia, devido à grande extensão territorial, o Brasil possui condições climáticas distintas, com região Centro-Sul e parte da região Nordeste, especialmente aquela de altitude mais elevada, caracterizando-se por produção de forragem em quantidade reduzida e de baixa qualidade, no período de outono-inverno $[1 ; 10]$.

A baixa produtividade de forragem durante épocas frias e secas do ano tem sido apontada como um dos fatores que mais contribuem para reduzidos índices de produtividades dos rebanhos [13]. Desta forma, no período de entressafra de pastagens, a utilização de forrageiras de inverno constitui-se em alternativa viável para amenizar os problemas de escassez de forragem nessas regiões, uma vez que essas espécies são economicamente viáveis, apresenta alta produtividade de massa seca, elevada qualidade nutricional e ótima aceitabilidade pelos animais. Dentre as espécies disponíveis destacam-se a aveia preta (Avena strigosa Schreb), a aveia branca (Avena sativa L.) e a aveia amarela (Avena byzantina $\mathrm{C}$. Koch) [21].

Embora as espécies de aveia sejam mais utilizadas na Região Sul do Brasil, Cardoso Junior et al. (2008) demonstraram boa produtividade da cultura em região de latitude tropical com maiores altitudes, contribuindo para amenizar a escassez de forragem na estação fria e seca, favorecendo, de forma expressiva, o rendimento dos rebanhos. No Sudoeste da Bahia, especialmente no município de Vitória da Conquista, região de altitude mais elevada, os autores verificaram que a aveia forrageira apresentou bom desempenho, com a produtividade de massa seca variando de $5.490 \mathrm{~kg} \mathrm{ha}^{-1}$, para o genótipo IA90056, a $6.891 \mathrm{~kg} \mathrm{ha}^{-1}$ para o genótipo São Carlos.

A produtividade de massa seca de aveia pode variar, entre outros fatores, de acordo com as características edafoclimáticas, a idade das plantas, o manejo ao qual a forrageira é submetida e a cultivar utilizada. $\mathrm{Na}$ avaliação do potencial forrageiro de um cultivar faz-se necessário, também, a determinação do valor nutritivo para os animais a que se destina [7], pois o mesmo influencia diretamente na produção do rebanho. A carência de programas de melhoramento com objetivo de selecionar espécies forrageiras com características desejáveis para implantação de sistemas de cultivo de inverno na região Nordeste do Brasil pode ser uma das maiores dificuldades encontrada pelos pecuaristas. Assim, torna-se necessária a realização de pesquisas que avaliem o comportamento dos genótipos cultivados na região Centro-Sul em diferentes condições ambientais para determinar os materiais mais adaptados a outras regiões do país.

$\mathrm{O}$ objetivo deste trabalho foi avaliar e selecionar genótipos de aveia adaptados às condições edafoclimáticas de Vitória da Conquista, BA, região tropical de altitude.

\section{MATERIAL E MÉTODOS}

O ensaio foi conduzido na área experimental da Universidade Estadual do Sudoeste da Bahia, em Vitória da Conquista, Bahia. O município está localizado nas coordenadas 1450'19" Latitude Sul e 40 50'19" Longitude Oeste, com altitude média de $928 \mathrm{~m}$. O clima, conforme classificação de Köppen, é do tipo Cwa (Tropical de Altitude), com precipitação média anual de 733,9 mm, concentrada nos meses de novembro a março e temperatura média anual de $20,2^{\circ} \mathrm{C}$, com a média máxima e mínima variando entre $26,4^{\circ} \mathrm{C}$ e $16,1^{\circ} \mathrm{C}$, respectivamente [20]. Os dados de precipitação pluviométrica e umidade relativa do ar, bem como as temperaturas médias mensais máximas e mínimas encontram-se na Figura 1. 


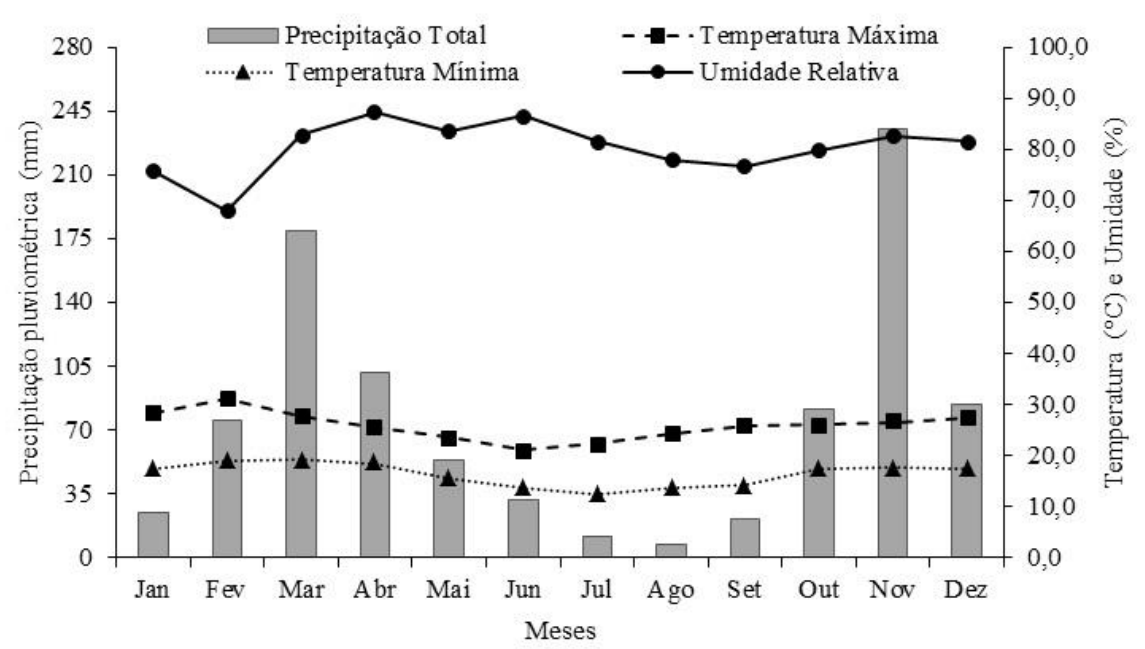

Figura 1:Precipitação total mensal, umidade relativa do ar e temperaturas máximas e mínimas, observadas no ano de condução do experimento. Fonte: Instituto Nacional de Meteorologia.

O solo onde se realizou o experimento foi classificado como Cambissolo Háplico Distrófico, de textura média, topografia suavemente ondulada, apresentando as seguintes características químicas: $\mathrm{pH}$ em água $=6,5 ; \mathrm{P}=15 \mathrm{mg} \mathrm{dm}^{-3}\left(\right.$ Extrator $\left.\mathrm{Mehlich}^{-1}\right) ; \mathrm{K}^{+}=0,58 \mathrm{cmolc} \mathrm{dm}^{-3}($ Extrator Mehlich $\left.{ }^{1}\right) ; \mathrm{Al}^{+}=0,0 \mathrm{cmolc} \mathrm{dm}^{-3}$ (Extrator $\left.\mathrm{KCl} 1 \mathrm{~mol} \mathrm{~L}^{-1}\right) ; \mathrm{Ca}^{2+}=4,5 \mathrm{cmolc} \mathrm{dm}^{-3}$ (Extrator $\mathrm{KCl} 1 \mathrm{~mol} \mathrm{~L}^{-1}$ ); $\mathrm{Mg}^{2+}=2,0 \mathrm{cmolc} \mathrm{dm}^{-3}$ (Extrator $\mathrm{KCl} 1 \mathrm{~mol} \mathrm{~L}^{-1}$ ); $\mathrm{H}^{+}=1,6 \mathrm{cmolc} \mathrm{dm}^{-3}$ (Extrator Solução SMP, $\mathrm{pH}$ 7,5 a 7,6); Soma de Bases $=7,1$ cmolc dm ${ }^{-3}$; Saturação por Alumínio (m) $=0 \%$; V = $82 \%$; CTC efetiva $(\mathrm{t})=7,1 \mathrm{cmolc} \mathrm{dm}^{-3}$; CTC a pH 7,0 $(\mathrm{T})=8,7 \mathrm{cmolc} \mathrm{dm}^{-3}$; Matéria Orgânica $=31 \mathrm{~g} \mathrm{dm}^{-3}$.

$\mathrm{O}$ solo foi preparado de forma convencional com uma aração e duas gradagens. A semeadura foi realizada em maio de 2006, manualmente, empregando-se a densidade de $70 \mathrm{~kg} \mathrm{ha}^{-1}$, a uma profundidade de $0,04 \mathrm{~m}$. No momento da semeadura, e com base nos resultados da análise química do solo, realizou-se adubação com superfosfato simples $\left(60 \mathrm{~kg} \mathrm{ha}^{-1} \mathrm{de}_{2} \mathrm{O}_{5}\right)$ e cloreto de potássio (60 $\mathrm{kg} \mathrm{ha}^{-1}$ de $\mathrm{K}_{2} \mathrm{O}$ ). A adubação nitrogenada variou de 80 a $120 \mathrm{~kg} \mathrm{ha}^{-1} \mathrm{de} \mathrm{N}$, de acordo a necessidade de cada genótipo, divididos em aplicações de $20 \mathrm{~kg} \mathrm{ha}^{-1}$ de $\mathrm{N}$, no momento do plantio; $20 \mathrm{~kg} \mathrm{ha}^{-1}$ de $\mathrm{N}$, aos 20 dias após o plantio e $20 \mathrm{~kg} \mathrm{ha}^{-1} \mathrm{de} \mathrm{N}$, imediatamente após cada corte de rebrota. Nos períodos de baixa disponibilidade hídrica foi utilizada irrigação suplementar via aspersão, duas vezes por semana, até o solo atingir a capacidade de campo. O controle de plantas daninhas foi feito manualmente até o estabelecimento da cultura.

Utilizou-se o delineamento experimental em blocos ao acaso, com nove tratamentos (genótipos) e três repetições. Os tratamentos foram constituídos pelos genótipos São Carlos, UPF 86081, FAPA 2, FAPA 43, UPF 15, IAPAR 61, UPF 19, IPR 126 e UFRGS 16. Cada parcela foi composta por cinco linhas de $6,0 \mathrm{~m}$ de comprimento, espaçadas entre si $0,2 \mathrm{~m}$, perfazendo área total de $6,0 \mathrm{~m}^{2}$. Uma área de $1,0 \mathrm{~m}^{2}$ de cada parcela não recebeu cortes e foi destinada à observação de características agronômicas. Para as avaliações das produtividades de massa verde, produtividade de massa seca e análise bromatológica, foram utilizadas as três linhas centrais, eliminando-se 0,5 $\mathrm{m}$ em cada extremidade, compondo-se uma área útil de $2,4 \mathrm{~m}^{2}$.

Foram realizadas avaliações de número de dias da emergência ao florescimento e número de dias da emergência ao amadurecimento dos grãos. Por meio do número de dias da emergência ao florescimento foi estabelecido o ciclo de crescimento dos genótipos de aveia forrageira em precoce (para menor de 80 dias), intermediário (para 81 a 110 dias) e tardio (para maiores de 111 dias), segundo a faixa estabelecida por Primavesi et al. (2006) [18].

Os cortes das plantas, em número de dois a três, foram feitos a $0,07 \mathrm{~m}$ da superfície do solo, de forma manual, utilizando-se facas, sendo que o primeiro corte foi realizado no início de emborrachamento. Os cortes das rebrotas foram realizados quando as plantas atingiram altura entre 35 e $40 \mathrm{~cm}$, sendo o último corte realizado por ocasião do aparecimento das primeiras inflorescências. 
Por ocasião dos cortes, a massa fresca colhida foi pesada para obtenção da produtividade de massa verde. Em seguida, foram retiradas amostras de forragens de aproximadamente $300 \mathrm{~g}$ e secas em estufa de circulação forçada de ar, a $65^{\circ} \mathrm{C}$, por 72 horas. Após a secagem, o material foi pesado e desintegrado em moinho tipo Willey, com peneira de $1 \mathrm{~mm}$, para posteriores análises laboratoriais. Foram determinados os teores de massa seca (MS), proteína bruta (PB), fibra insolúvel em detergente neutro (FDN), fibra insolúvel em detergente ácido (FDA) e digestibilidade in vitro da matéria seca (DIVMS), conforme descrito por Silva e Queiroz (2002) [19].

Os dados foram testados quanto à normalidade e homogeneidade de variâncias, por meio dos testes Lilliefors e Cochran, respectivamente e, posteriormente, submetidos à análise de variância, a $5 \%$ de probabilidade. As médias dos tratamentos foram comparadas pelo teste de agrupamento de Scott-Knott, a 5\% de probabilidade. Utilizou-se o programa SAEG, v. 9.1.

\section{RESULTADOS E DISCUSSÃO}

Os valores de produtividade de massa verde dos genótipos de aveia em três cortes e o valor total acumulado durante o ciclo de crescimento encontram-se na Tabela 1. Foi constatada diferença ( $\mathrm{p}<$ $0,05)$ entre genótipos no primeiro corte, com formação de dois grupos pelo critério de Scott-Knott. Verificou-se que os genótipos UPF 86081(55.139 $\left.\mathrm{kg} \mathrm{ha}^{-1}\right)$, UPF 19 (43.889 $\mathrm{kg} \mathrm{ha}^{-1}$ ) e UFRGS 16 $\left(41.667 \mathrm{~kg} \mathrm{ha}^{-1}\right)$ apresentaram maiores médias, destacando seu potencial para produção de forragem na região. Isso indica que esses três genótipos são materiais de mais rápido estabelecimento, uma vez que apresentaram melhores produtividades no primeiro corte. Em regiões tropicais de altitude, caracterizadas por temperaturas amenas no inverno e com possibilidade de irrigação suplementar, cultivares com alta produtividade de massa verde, principalmente no primeiro corte, tornam-se de grande importância para alimentação animal nesse período.

Rápido estabelecimento e elevada porcentagem de emergência das plantas são fatores importantes na escolha de uma forrageira, principalmente para a aveia, pois são utilizadas como alternativas para amenizar a escassez de forragem na estação fria e seca [21].

Tabela 1: Produtividade de massa verde (MV) de genótipos de aveia forrageira, Vitória da Conquista - BA, 2016.

\begin{tabular}{lcccc}
\hline \multirow{2}{*}{ Genótipos } & \multicolumn{3}{c}{ Massa verde $\left(\mathrm{kg} \mathrm{ha}^{-1}\right)$} & Total \\
\cline { 2 - 4 } & $1^{\text {o }}$ corte & $2^{\text {o }}$ corte & $3^{\text {o corte }}$ & 65.417 \\
\hline UPF 86081 & $55.139 \mathrm{~A}$ & 6.339 & 3.889 & 53.958 \\
UPF 19 & $43.889 \mathrm{~A}$ & 6.875 & 3.194 & 57.431 \\
UFRGS 16 & $41.667 \mathrm{~A}$ & 10.972 & 4.792 & 49.514 \\
FAPA 43 & $37.431 \mathrm{~B}$ & 7.361 & 4.722 & 43.333 \\
FAPA 2 & $32.361 \mathrm{~B}$ & 6.389 & 4.583 & 40.833 \\
IPR 126 & $32.361 \mathrm{~B}$ & 8.472 & -- & 37.708 \\
IAPAR 61 & $31.875 \mathrm{~B}$ & 5.833 & -- & 47.153 \\
UPF 15 & $31.389 \mathrm{~B}$ & 10.278 & 5.486 & 44.306 \\
São Carlos & $30.695 \mathrm{~B}$ & 8.333 & 5.278 & 48.850 \\
\hline Média & 37.423 & 7.878 & 4.563 & 21,66 \\
\hline CV $(\%)$ & 21,41 & 28,37 & 35,58 & \\
\hline
\end{tabular}

Grupo de médias seguidas de letras iguais na coluna não diferem entre si, pelo teste Scott-Knott, a 5\% de probabilidade.

No segundo e terceiro corte e no total acumulado entre os cortes não houve diferença de produtividade de massa verde entre os genótipos $(\mathrm{p}>0,05)$. A produtividade do segundo corte variou de 5.833 a $10.972 \mathrm{~kg} \mathrm{ha}^{-1}$ e do terceiro corte variou de $3.194 \mathrm{~kg} \mathrm{ha}^{-1}$ a $5.486 \mathrm{~kg} \mathrm{ha}^{-1}$. A massa verde total variou de $37.708 \mathrm{~kg} \mathrm{ha}^{-1} \mathrm{a} 65.417 \mathrm{~kg} \mathrm{ha}^{-1}$ e apresentou média geral de $48.850 \mathrm{~kg} \mathrm{ha}^{-}$ ${ }^{1}$ (Tabela 1).

Na maioria dos genótipos foi possível efetuar um terceiro corte, com exceção do IPR 126 e o IAPAR 61 (Tabela 1), o que pode ser atribuído a alta capacidade de rebrota e formação de novos perfilhos após os cortes, associados às condições edafoclimáticas locais (com temperaturas 
variando entre 10 e $25^{\circ} \mathrm{C}$ no período de inverno - Figura 1), favoráveis ao desenvolvimento das plantas de aveia.

Além disso, a adubação nitrogenada em cobertura, feita após cada corte, pode ter acelerado os processos de divisão e alongamento celular, resultando em maior crescimento vegetativo e acúmulo de biomassa [12].

A produtividade de massa verde é uma das principais características avaliadas na seleção de uma forrageira. Maiores valores de massa verde no primeiro corte podem servir de referência para a escolha do genótipo a ser utilizado para produção de silagem. Além de ser um parâmetro para dimensionamento do silo [5], esta característica contribui também para diluição dos custos de implantação da cultura por elevar a produtividade [17]. Ao contrário, genótipos com produtividade de massa verde bem distribuída ao longo de vários cortes, tornam-se desejáveis quando se opta pelo pastejo direto dos animais na área de cultivo. Entretanto, em regiões de clima tropical com inverno ameno, a seleção de genótipos com elevado acúmulo de biomassa no primeiro corte é de grande importância, por permitir produção de silagem e possibilitar armazenamento da forragem em períodos com escassez de alimento. Nesse sentido, os genótipos UPF 86081, UPF 19 e UFRGS 16 mostraram-se mais adaptados ao cultivo nas condições edafoclimáticas de Vitória da Conquista BA, produzindo juntos cerca de $42 \%$ do total de massa verde colhida no primeiro corte (Tabela 1).

Cardoso Júnior et al. (2008)[1], a partir de um ensaio realizado no mesmo município, verificaram produtividade de massa verde, aos 60 dias (primeiro corte), de $21.111 \mathrm{~kg} \mathrm{ha}^{-1}, 24.792 \mathrm{~kg} \mathrm{ha}^{-1}$, $18.611 \mathrm{~kg} \mathrm{ha}^{-1}, 23.653 \mathrm{~kg} \mathrm{ha}^{-1}, 22.014 \mathrm{~kg} \mathrm{ha}^{-1} \mathrm{e}$ aos 120 dias (segundo corte) de $14.604 \mathrm{~kg} \mathrm{ha}^{-1}$, $14.589 \mathrm{~kg} \mathrm{ha}^{-1}, 9.167 \mathrm{~kg} \mathrm{ha}^{-1}, 17.190 \mathrm{~kg} \mathrm{ha}^{-1}, 19.028 \mathrm{~kg} \mathrm{ha}^{-1}$ para os genótipos São Carlos, UPF 15, UPF 19, UFRGS 16 e IAPAR 61, respectivamente, adubadas com superfosfato simples e cloreto de potássio, na dosagem equivalente a $60 \mathrm{~kg} \mathrm{ha}^{-1}$ de $_{2} \mathrm{P}_{5}$ e $60 \mathrm{~kg} \mathrm{ha}^{-1}$ de $\mathrm{K}_{2} \mathrm{O}$ no plantio e adubação nitrogenada na forma de uréia, na quantidade de $100 \mathrm{~kg} \mathrm{ha}^{-1} \mathrm{de} \mathrm{N}$, fracionada em três aplicações em cobertura.

Com relação à produtividade de massa seca (Tabela 2), observou-se, no primeiro corte, que os valores variaram de $3.406 \mathrm{~kg} \mathrm{ha}^{-1}$ a $7.638 \mathrm{~kg} \mathrm{ha}^{-1}$ entre os genótipos São Carlos e UPF 86081, respectivamente, com média geral de $5.537 \mathrm{~kg} \mathrm{ha}^{-1}$. Os genótipos foram divididos em três grupos pelo teste de Scott-Knott, com UPF86081, IPR126 e IAPAR61 apresentando maiores produtividade de massa seca. No segundo e terceiro cortes, não houve diferença significativa $(p>0,05)$ entre os genótipos, e os valores de massa seca alternaram entre $908 \mathrm{~kg} \mathrm{ha}^{-1} \mathrm{e} 1.716 \mathrm{~kg} \mathrm{ha}^{-1}$ (corte 2) e entre $494 \mathrm{~kg} \mathrm{ha}^{-1}$ e $1.040 \mathrm{~kg} \mathrm{ha}^{-1}$ (corte 3 ).

Tabela 2. Produtividade de massa seca (MS) de genótipos de aveia forrageira, Vitória da Conquista-BA, 2016.

\begin{tabular}{lcccc}
\hline Genótipos & \multicolumn{3}{c}{ Massa seca $\left(\mathrm{kg} \mathrm{ha}^{-1}\right)$} & Total \\
\cline { 2 - 4 } & $1^{\circ}$ corte & $2^{\circ}$ corte & $3^{\circ}$ corte & $9.148 \mathrm{~A}$ \\
\hline UPF 86081 & $7.638 \mathrm{~A}$ & 908 & 602 & $6.348 \mathrm{~B}$ \\
UPF 19 & $4.923 \mathrm{C}$ & 931 & 494 & $6.322 \mathrm{~B}$ \\
UFRGS 16 & $4.475 \mathrm{C}$ & 1.178 & 669 & $8.022 \mathrm{~A}$ \\
FAPA 43 & $5.984 \mathrm{~B}$ & 1.168 & 870 & $6.905 \mathrm{~B}$ \\
FAPA 2 & $4.892 \mathrm{C}$ & 1.027 & 986 & $9.295 \mathrm{~A}$ \\
IPR 126 & $7.579 \mathrm{~A}$ & 1.716 & -- & $8.611 \mathrm{~A}$ \\
IAPAR 61 & $7.427 \mathrm{~A}$ & 1.184 & - & $5.766 \mathrm{~B}$ \\
UPF 15 & $3.513 \mathrm{C}$ & 1.213 & 1.040 & $5.133 \mathrm{~B}$ \\
São Carlos & $3.406 \mathrm{C}$ & 1.073 & 654 & 7.283 \\
\hline Média & 5.537 & 1.155 & 759 & 15,37 \\
\hline CV $(\%)$ & 15,15 & 25,00 & 29,75 & .5 \\
\hline
\end{tabular}

Grupo de médias seguidas de letras iguais na coluna não diferem entre si, pelo teste Scott-Knott, a 5\% de probabilidade.

A produtividade de massa seca no primeiro corte dos genótipos avaliados no presente estudo foi expressiva quando comparada a outros trabalhos (Tabela 2). Fão et al. (2006) [4] ao avaliarem cultivares de aveia no município de Cruz Alta, RS, onde a temperatura e a pluviosidade média anual 
é de $20^{\circ} \mathrm{C}$ e $1.300 \mathrm{~mm}$, respectivamente, e o clima é do tipo Cfa, segundo classificação de Koppen, obtiveram produtividade de massa seca de $1.024 \mathrm{~kg} \mathrm{ha}^{-1}, 1.271 \mathrm{~kg} \mathrm{ha}^{-1}, 1.265 \mathrm{~kg} \mathrm{ha}^{-1}, 1.671 \mathrm{~kg} \mathrm{ha}^{-}$ ${ }^{1}$ e $1.649 \mathrm{~kg} \mathrm{ha}^{-1}$, para os genótipos IAPAR 61, IPR 126, FAPA 2 e FAPA 43, respectivamente. Em pesquisas conduzidas em Jaboticabal - SP, Moreira et al. (2005) [15] obtiveram produções de massa seca para os genótipos UPF86081 e São Carlos de 5,1 e 4,3 t ha ${ }^{-1}$, respectivamente, no primeiro corte, aos 64 dias após a semeadura. Cardoso Júnior et al. (2008) [1], em Vitória da Conquista, BA, verificaram que os genótipos São Carlos, UPF15, UP19, UFRG16 e IAPAR61 produziram $3.643 \mathrm{~kg} \mathrm{ha}^{-1}, 3.307 \mathrm{~kg} \mathrm{ha}^{-1}, 3.549 \mathrm{~kg} \mathrm{ha}^{-1}, 3.098 \mathrm{~kg} \mathrm{ha}^{-1}$ e $2.879 \mathrm{~kg} \mathrm{ha}^{-1}$ de massa seca, respectivamente, aos 60 dias após a emergência.

Com relação à produtividade total de massa seca (Tabela 2), os genótipos foram divididos em dois grupos, destacando-se com maiores médias o agrupamento formado por UPF 86081, FAPA 43, IPR126 e IAPAR61, que alcançaram, respectivamente, $9.148 \mathrm{~kg} \mathrm{ha}^{-1}, 8.022 \mathrm{~kg} \mathrm{ha}^{-1}, 9.295 \mathrm{~kg}$ $\mathrm{ha}^{-1}$ e $8.611 \mathrm{~kg} \mathrm{ha}^{-1}$ de MS. A média geral para essa característica foi de $7.283 \mathrm{~kg} \mathrm{ha}^{-1}$. Tafernaberri Júnior et al. (2012) [21], analisando genótipos de aveia com a finalidade de identificar os mais promissores para produção de forragem, obtiveram produções de massa seca total (soma de quatro cortes) que variaram de 595 a $949 \mathrm{~kg} \mathrm{ha}^{-1}$, para o município de Eldorado do Sul - RS, e de 441 a $919 \mathrm{~kg} \mathrm{ha}^{-1}$, em Bagé - RS.

$\mathrm{Na}$ Tabela 3, encontram-se os teores de proteína bruta dos genótipos de aveia, em três cortes. Foi observada diferença entre os genótipos, nos cortes 1,2 e 3 ( $\mathrm{p}<0,05)$. No primeiro corte, houve formação de três grupos, sendo o primeiro formado somente pelo genótipo UPF15, que apresentou teor de proteína bruta de 19,49\%. No segundo corte, o grupo formado pelos genótipos UPF 86081, UPF 19, UFRGS 16, FAPA 43, FAPA 2, UPF 15 e São Carlos foi o que apresentou maiores teores de $\mathrm{PB}$, com médias variando de $22,01 \%$ a $26,02 \%$. No terceiro corte, houve formação de apenas dois agrupamentos, nos quais os genótipos UPF 19 (20,87\%), UFRGS $16(19,305)$ e São Carlos $(23,30 \%)$ apresentaram médias superiores de proteína bruta.

Tabela 3. Teores médios de proteína bruta $(P B)$ de genótipos de aveia forrageira, Vitória da Conquista-BA, 2016.

\begin{tabular}{lccc}
\hline \multirow{2}{*}{ Genótipos } & \multicolumn{3}{c}{ Proteína bruta $(\%)$} \\
\cline { 2 - 4 } & $1^{\text {o } \text { corte }}$ & $2^{\text {o } \text { corte }}$ & $3^{\text {o corte }}$ \\
\hline UPF 86081 & $10,50 \mathrm{C}$ & $22,01 \mathrm{~A}$ & $17,60 \mathrm{~B}$ \\
UPF 19 & $14,14 \mathrm{C}$ & $24,73 \mathrm{~A}$ & $20,87 \mathrm{~A}$ \\
UFRGS 16 & $16,21 \mathrm{~B}$ & $24,78 \mathrm{~A}$ & $19,30 \mathrm{~A}$ \\
FAPA 43 & $13,60 \mathrm{C}$ & $26,02 \mathrm{~A}$ & $17,58 \mathrm{~B}$ \\
FAPA 2 & $14,90 \mathrm{~B}$ & $22,37 \mathrm{~A}$ & $16,25 \mathrm{~B}$ \\
IPR 126 & $12,16 \mathrm{C}$ & $13,19 \mathrm{C}$ & -- \\
IAPAR 61 & $15,14 \mathrm{~B}$ & $19,10 \mathrm{~B}$ & - \\
UPF 15 & $19,49 \mathrm{~A}$ & $23,51 \mathrm{~A}$ & $14,31 \mathrm{~B}$ \\
São Carlos & $16,59 \mathrm{~B}$ & $26,02 \mathrm{~A}$ & $23,30 \mathrm{~A}$ \\
\hline Média & 14,75 & 22,41 & 18,46 \\
\hline CV $(\%)$ & 13,60 & 14,30 & 14,96 \\
\hline
\end{tabular}

Grupo de médias seguidas de letras iguais na coluna não diferem entre si, pelo teste Scott-Knott, a $5 \%$ de probabilidade.

Em média, o teor de proteína bruta aumentou 51,9\% do primeiro para o segundo corte (Tabela 3). Isso pode ser atribuído ao efeito da adubação nitrogenada, em que foram utilizados $20 \mathrm{~kg} \mathrm{ha}^{-1}$ de $\mathrm{N}$, imediatamente após cada corte de rebrota. No terceiro corte, para a maioria dos genótipos, houve redução no teor de proteína bruta, o que pode estar associado ao avançado estádio de desenvolvimento das plantas, com maior produção de colmos e redução das folhas. Esse comportamento também foi verificado por Floss et al. (2007) [8], que detectaram redução no teor de proteína bruta em função do estágio de maturação das plantas de aveia, variando de 24\%, aos 14 dias após a emergência, para 4,9\%, aos 126 dias após a emergência.

Em geral, os teores de proteína bruta encontrados no presente estudo estão semelhantes aos obtidos por Ferolla et al. (2008) [6], em Campos dos Goytacazes - RJ. Meinerz et al. (2011) [14], 
avaliando diferentes cultivares e linhagens de aveias branca e preta, verificaram que durante o primeiro corte, o teor de proteína bruta variou de 23,83 a 26,05\% e, no segundo e terceiro cortes, a variação foi de 22,46 a $24,13 \%$ e de 15,86 a $18,93 \%$, respectivamente, evidenciando assim o efeito da idade da planta e da época de corte na qualidade nutricional desta forragem. A constituição de compostos nitrogenados oscila durante o ciclo da planta, pois a parede das células vegetais cresce para proporcionar estabilidade estrutural e conferir proteção aos órgãos reprodutores e às sementes [6].

Quanto aos teores de fibra em detergente neutro, verificou-se que houve diferença $(p<0,05)$ entre os genótipos, em todos os cortes (Tabela 4). No primeiro corte, notou-se a formação de três grupos, onde o grupo formado pelos genótipos FAPA 43, FAPA 2, IPR 126, IAPAR 61, UPF 15 e São Carlos obteve menores valores de fibra em detergente neutro, com média variando entre $52,33 \%$ e 56,31\%. No segundo corte, os genótipos UPF 86081, UPF 19, UFRGS 16, FAPA 43, FAPA 2, UPF 15 e São Carlos constituíram o grupo com os menores percentuais de FDN, em média 49,89\%. No terceiro corte, o grupo formado pelos genótipos UPF 86081, UPF 19, UFRGS 16, FAPA 2 e São Carlos apresentou teor de fibra em detergente neutro cerca de 17\% inferior ao grupo formado pelos genótipos FAPA 43 e UPF 15. Em geral, os valores médios de FDN estão semelhantes aos obtidos por Cecato et al. (2001) [2] que, ao avaliar diferentes cultivares e linhagens de aveia em Maringá, Paraná, verificaram variação de 42,66\% a 61,55\%.

Tabela 4. Teores médios de fibra em detergente neutro (FDN) de genótipos de aveia forrageira, Vitória da Conquista - BA, 2016.

\begin{tabular}{lccc}
\hline \multirow{2}{*}{ Genótipos } & \multicolumn{3}{c}{ Fibra em detergente neutro $(\%)$} \\
\cline { 2 - 4 } & $1^{\text {o corte }}$ & $2^{\text {o }}$ corte & $3^{\circ}$ corte \\
\hline UPF 86081 & $61,02 \mathrm{C}$ & $50,01 \mathrm{~A}$ & $51,62 \mathrm{~A}$ \\
UPF 19 & $63,49 \mathrm{C}$ & $50,53 \mathrm{~A}$ & $52,01 \mathrm{~A}$ \\
UFRGS 16 & $58,35 \mathrm{~B}$ & $51,49 \mathrm{~A}$ & $50,49 \mathrm{~A}$ \\
FAPA 43 & $56,16 \mathrm{~A}$ & $46,78 \mathrm{~A}$ & $58,26 \mathrm{~B}$ \\
FAPA 2 & $52,52 \mathrm{~A}$ & $49,72 \mathrm{~A}$ & $51,71 \mathrm{~A}$ \\
IPR 126 & $52,33 \mathrm{~A}$ & $56,95 \mathrm{~B}$ & - \\
IAPAR 61 & $52,77 \mathrm{~A}$ & $60,88 \mathrm{C}$ & - \\
UPF 15 & $54,52 \mathrm{~A}$ & $50,93 \mathrm{~A}$ & $61,98 \mathrm{~B}$ \\
São Carlos & $55,67 \mathrm{~A}$ & $49,63 \mathrm{~A}$ & $51,86 \mathrm{~A}$ \\
\hline Média & 56,31 & 51,88 & 53,99 \\
\hline CV $(\%)$ & 3,69 & 4,23 & 5,95 \\
\hline
\end{tabular}

Grupo de médias seguidas de letras iguais na coluna não diferem entre si, pelo teste Scott-Knott, a 5\% de probabilidade.

Houve diferença significativa $(\mathrm{p}<0,05)$ entre genótipos tanto no primeiro quanto no segundo corte para os teores médios de fibra em detergente ácido (Tabela 5), sendo possível a formação de dois agrupamentos. No primeiro corte, o grupo formado pelos genótipos UFRGS 16, FAPA 43, FAPA 2, IPR 126, IAPAR 61, UPF 15 e São Carlos apresentou menores teores de FDA, com média variando entre $26,83 \%$ a $31,65 \%$. No segundo corte, menores teores de FDA foram obtidos pelo agrupamento dos genótipos FAPA 43, FAPA 2, UPF 15 e São Carlos. No terceiro corte, não houve diferença significativa $(\mathrm{p}>0,05)$ entre os genótipos, com teores de fibra em detergente ácido variando de $27,12 \%$ a $32,92 \%$.

Em média, o teor de FDA no primeiro corte foi de 31,02\%; no segundo corte, a média foi de $27,51 \%$ e no último corte, $29,71 \%$. As forragens que apresentam valores de FDA acima de $40 \%$ proporcionam baixo consumo pelos animais e menor digestibilidade [16], confirmando assim, que os genótipos estudados apresentaram valores considerados adequados. Resultados semelhantes foram encontrados por Meinerz et al. (2011) [14], ao avaliarem genótipos de cereais de inverno, entre estes, variedades de aveia-preta e aveia-branca, que apresentaram uma variação de $21,14 \%$ a $30,51 \%$ de fibra em detergente ácido. Moreira et al. (2005) [15] observaram menores valores de FDA para o genótipo UPF 86081 dentre os genótipos estudados. 
Tabela 5. Teores médios de fibra em detergente ácido(FDA) de genótipos de aveia forrageira, Vitória da Conquista - BA, 2016.

\begin{tabular}{lccc}
\hline \multirow{2}{*}{ Genótipos } & \multicolumn{3}{c}{ Fibra em detergente ácido (\%) } \\
\cline { 2 - 4 } & $1^{\text {o } \text { corte }}$ & $2^{\text {o }}$ corte & $3^{\text {o }}$ corte \\
\hline UPF 86081 & $37,63 \mathrm{~B}$ & $28,02 \mathrm{~B}$ & 28,15 \\
UPF 19 & $35,47 \mathrm{~B}$ & $28,52 \mathrm{~B}$ & 28,12 \\
UFRGS 16 & $31,65 \mathrm{~A}$ & $28,02 \mathrm{~B}$ & 31,14 \\
FAPA 43 & $30,12 \mathrm{~A}$ & $25,53 \mathrm{~A}$ & 31,77 \\
FAPA 2 & $28,97 \mathrm{~A}$ & $24,14 \mathrm{~A}$ & 27,12 \\
IPR 126 & $28,75 \mathrm{~A}$ & $30,39 \mathrm{~B}$ & - \\
IAPAR 61 & $26,83 \mathrm{~A}$ & $29,35 \mathrm{~B}$ & -- \\
UPF 15 & $29,52 \mathrm{~A}$ & $27,16 \mathrm{~A}$ & 32,92 \\
São Carlos & $30,26 \mathrm{~A}$ & $26,46 \mathrm{~A}$ & 28,76 \\
\hline Média & 31,02 & 27,51 & 29,71 \\
\hline CV $(\%)$ & 4,35 & 7,28 & 15,18 \\
\hline
\end{tabular}

Grupo de médias seguidas de letras iguais na coluna não diferem entre si, pelo teste Scott-Knott, a 5\% de probabilidade.

Quanto aos valores de digestibilidade in vitro da matéria seca observa-se a formação de dois grupos no primeiro corte, com os genótipos UFRGS 16, FAPA 43, FAPA 2, IPR 126, IAPAR 61, UPF 15 e São Carlos apresentando maiores médias, variando de 79,57\% a 84,74\% (Tabela 6). No segundo corte, os valores de DIVMS do grupo formado por UFRGS 16, UPF 15 e São Carlos foram aproximadamente $10 \%$ superiores ao do terceiro grupo, que apresentou a menor digestibilidade $(80,74 \%)$. No terceiro corte, não houve diferença significativa $(\mathrm{p}>0,05)$ entre os genótipos, com variação de $73,77 \%$ a $84,47 \%$ de DIVMS e média geral de $80,27 \%$.

Tabela 6. Porcentagem de digestibilidade in vitro da matéria seca (DIVMS) de genótipos de aveia forrageira, Vitória da Conquista-BA, 2016.

\begin{tabular}{lccc}
\hline \multirow{2}{*}{ Genótipos } & \multicolumn{3}{c}{ Digestibilidade in vitro da matéria seca (\%) } \\
\cline { 2 - 4 } & $1^{\circ}$ corte & $2^{\text {o }}$ corte & $3^{\text {o }}$ corte \\
\hline UPF 86081 & $72,21 \mathrm{~B}$ & $80,74 \mathrm{C}$ & 73,77 \\
UPF 19 & $74,66 \mathrm{~B}$ & $85,48 \mathrm{~B}$ & 81,84 \\
UFRGS 16 & $80,38 \mathrm{~A}$ & $87,94 \mathrm{~A}$ & 84,47 \\
FAPA 43 & $79,57 \mathrm{~A}$ & $85,23 \mathrm{~B}$ & 78,70 \\
FAPA 2 & $82,65 \mathrm{~A}$ & $84,29 \mathrm{~B}$ & 81,19 \\
IPR 126 & $81,16 \mathrm{~A}$ & $75,78 \mathrm{D}$ & -- \\
IAPAR 61 & $79,87 \mathrm{~A}$ & $76,28 \mathrm{D}$ & -- \\
UPF 15 & $84,74 \mathrm{~A}$ & $88,21 \mathrm{~A}$ & 76,46 \\
São Carlos & $81,54 \mathrm{~A}$ & $89,74 \mathrm{~A}$ & 85,45 \\
\hline Média & 79,64 & 83,74 & 80,27 \\
\hline CV (\%) & 2,70 & 2,54 & 6,26 \\
Grupo de médias seguidas de letras iguais na coluna não diferem entre si, pelo teste Scott-Knott, a 5\% de \\
probabilidade.
\end{tabular}

Segundo Gordin (2011) [9], a digestibilidade pode ser definida como a proporção do alimento consumido que é digerida e metabolizada pelo animal. Sendo assim, quanto mais próximo a DIVMS de 100\%, melhor será a alimentação do animal. Valores menores foram obtidos por Moreira et al. (2005) [15], que ao avaliarem diferentes genótipos de aveia para produção de forragem, encontraram uma variação de 62,1 a $74,8 \%$ para o primeiro corte e 50,6 a $58,7 \%$ para o segundo corte. Maiores valores de DIVMS encontrados neste trabalho, comparados a estes autores, provavelmente ocorreram devido à época da semeadura e as diferentes condições edafoclimáticas do local onde foi realizado este experimento, que proporcionaram menores valores dos 
componentes da parede celular e, consequentemente, maior valor de DIVMS, indicando assim a possível utilização da aveia forrageira em regiões tropicais de altitude elevada.

Os genótipos apresentaram ciclos distintos (Tabela 7). O número de dias da emergência ao florescimento variou de 68 a 136 e o número de dias da emergência ao amadurecimento dos grãos variou de 95 a 169 , indicando que o ambiente onde foram cultivadas estas forrageiras exerceu grande influência sobre o ciclo fenológico da cultura.

Tabela 7. Número de dias da emergência ao florescimento (DF), número de dias da emergência ao amadurecimento dos grãos (DA) e ciclo de crescimento de genótipos de aveia forrageira, Vitória da Conquista - BA, 2016.

\begin{tabular}{lccc}
\hline Genótipos & DF & DA & Ciclo de crescimento \\
\hline UPF 86081 & 79 & 116 & Precoce \\
UPF 19 & 61 & 95 & Precoce \\
UFRGS 16 & 77 & 112 & Precoce \\
FAPA 43 & 134 & 168 & Tardio \\
FAPA 2 & 129 & 165 & Tardio \\
IPR 126 & 136 & 169 & Tardio \\
IAPAR 61 & 130 & 162 & Tardio \\
UPF 15 & 76 & 108 & Precoce \\
São Carlos & 68 & 106 & Precoce \\
\hline
\end{tabular}

Demétrio et al. (2012) [3], ao estudarem produtividade de biomassa de cultivares de aveia sob diferentes manejos de corte, no município de Santa Helena, PR, observaram o mesmo número de dias da emergência ao florescimento encontrado neste trabalho, para o genótipo IAPAR 61, que foi de 130 dias da emergência ao florescimento. Para os genótipos IPR 126 e FAPA 2, os mesmos autores encontraram números de dias aproximados, a este mesmo estudo, de 130 e 137 dias para o florescimento, respectivamente, comprovando, assim, uma variação devido provavelmente às condições ambientais diferentes de cada região.

No Tabela 7, observa-se que os genótipos São Carlos, UPF 19, UPF 15, UFRGS 16 e UPF 86081 tiveram o ciclo vegetativo precoce, enquanto que os genótipos FAPA 2, IAPAR 61, FAPA 43 e IPR 126 apresentaram ciclo tardio. Segundo Primavesi et al. (2006) [18], está cada vez mais difícil estabelecer faixas em dias para classificação dos ciclos dos genótipos, devido principalmente ao melhoramento genético que tem conseguido encurtar cada vez mais esse ciclo. Os mesmos autores, ao avaliarem diferentes genótipos de aveia em um ensaio realizados na estação experimental da Embrapa Pecuária Sudeste, em São Carlos, SP, observaram que os genótipos São Carlos, UPF 86081, UPF 15 e UFRGS 16 tiveram ciclo vegetativo tardio, enquanto que neste trabalho, ao serem cultivados em região tropical de altitude, os mesmos genótipos obtiveram ciclo precoce, mostrando variações do ciclo vegetativo em função do local de cultivo.

\section{CONCLUSÃO}

Os genótipos UPF 86081, UPF 19 e UFRGS 16 apresentam maior capacidade de acúmulo de biomassa verde. Os genótipos UPF 86081, IPR 126 e IAPAR 61 alcançam maior produtividade de massa seca nas condições edafoclimáticas de Vitória da Conquista - BA.

O genótipo UPF 15 apresenta maior teor de proteína bruta e os genótipos FAPA 43, FAPA 2, IPR 126, IAPAR 61, UPF 15 e São Carlos melhor desempenho bromatológico com reduzido conteúdo de fibras e maior digestibilidade da matéria seca.

O uso da aveia forrageira no período seco e frio do ano, em regiões tropicais de altitude, pode ser uma alternativa para suprir de alimentos de qualidade e promover a manutenção do desempenho dos animais no período de estiagem. 


\section{REFERÊNCIAS BIBLIOGRÁFICAS}

1. Cardoso Júnior N dos S, Viana AES, Oliveira JC de, Figueiredo MP de, Costa HA, Rebouças GMN. Rendimento de aveia forrageira cultivada no Sudoeste da Bahia. Magistra, 2008; 20(4):406-412.

2. Cecato U, Rêgo FC de A, Gomes JAN, Canto MW do, Jobim CC, Coneglian S, Moreira FB. Produção e composição química em cultivares e linhagens de aveia (Avena spp). Acta Scientiarum, 2001; 23(4):775780. doi: 10.4025/actascianimsci.v23i0.2578.

3. Demétrio JV, Costa ACT da, Oliveira PSR de. Produção de biomassa de cultivares de aveia sob diferentes manejos de corte. Pesquisa Agropecuária Tropical, 2012; 42(2):198-205. doi: 10.1590/S198340632012000200011.

4. Fão V de M, Boss R, Lima AS de. Ensaio nacional de aveias forrageiras em Cruz Alta, RS, em 2005. In: Reunião da Comissão Brasileira de Pesquisa de Aveia, 26. 2006, Guarapuava. Resultados experimentais...Guarapuava: Iapar, 2006; pp. 141-143.

5. Ferrari Júnior E, Possenti RA, Lima ML, Nogueira JR, Andrade JB de. Características, composição química e qualidade de silagens de oito cultivares de milho. Boletim de Indústria Animal, 2005; 62(1):1927.

6. Ferolla FS, Vásquez HM, Silva JFC da, Viana AP, Domingues FN, Lista FN. Composição bromatológica e fracionamento de carboidratos e proteínas de aveia-preta e triticale sob corte e pastejo. Revista Brasileira de Zootecnia, 2008; 37(2):197-204. doi: 10.1590/S1516-35982008000200004.

7. Fisher LJ, Fowler DB. Predicted forage value of whole plant cereals. Canadian Journal of Plant Science, 1975; 55(4):975-986. doi: 10.4141/cjps75-154.

8. Floss EL, Palhano AL, Soares Filho CV, Premazzi LM. Crescimento, produtividade, caracterização e composição química da aveia branca. Acta Scientiarum Animal Science, 2007; 29(1):1-7. doi: 10.4025/actascianimsci.v29i1.241.

9. Gordin CL. Degradabilidade ruminal e digestibilidade in vitro da matéria seca de gramíneas de Cynodon spp em quatro idades de rebrota. 2011. 79p. Dissertação (Mestrado em Zootecnia) - Universidade Federal da Grande Dourados, MS.

10. Hoffmann A, Moraes EHBK de, Mousquer CJ, Simioni TA, Junior Gomes F, Ferreira VB, Silva HM da. Produção de bovinos de corte no sistema de pasto-suplemento no período seco. Nativa, 2014; 2(2):119130. doi: 10.14583/2318-7670.v02n02a10.

11. Instituto Nacional de Meteorologia. Dados Meteorológicos, 2006. Disponível em:<http://www.inmet.gov.br>.

12. Jehangir I A, Khan HU, Khan MH, Ur-Rasool F, Bhat RA, Mubarak T, Bhat MA, Rasool S. Effect of sowing dates, fertility levels and cutting managements on growth, yield and quality of oats (Avena sativa L.). African Journal of Agricultural Research, 2013; 8(7):648-651. doi: 10.5897/AJAR12.1677.

13. Lopes MN, Pompeu RCFF, Silva RG da, Regadas Filho JGL, Beserra LT, Lacerda CF de. Trocas gasosas e índices de crescimento em capim-braquiária manejado sob lâminas de irrigação e idades de crescimento. Revista Agro@mbiente Online, 2013; 7(1):10-17. doi: 10.18227/1982-8470ragro.v7i1.930.

14. Meinerz GR, Olivo CJ, Fontaneli RS, Agnolin CA, Fontaneli RS, Horst T, Viégas J, Bem CM de. Valor nutritivo da forragem de genótipos de cereais de inverno de duplo propósito. Revista Brasileira de Zootecnia, 2011; 40(6):1173-1180. doi: 10.1590/S1516-35982011000600003.

15. Moreira AL, Ruggieri AC, Reis RA, Seixas PF, Pedreira MS, Godoy R. Avaliação de aveia preta e de genótipos de aveia amarela para produção de forragem. ARS Veterinária, 2005; 21:175-182. doi: 10.15361/2175-0106.2005v21n4p175-182.

16. Nussio LG, Manzano RP, Pedreira CGS. Valor alimentício em plantas do gênero Cynodon. Simpósio sobre Manejo da Pastagem, 15. Anais... FEALQ/ESALQ. Piracicaba, 1998; pp. 203-242.

17. Paziani S de F, Duarte AP, Nussio LG, Gallo PB, Bittar CMM, Zopollatto M, Reco PC. Características agronômicas e bromatológicas de híbridos de milho para produção de silagem. Revista Brasileira de Zootecnia, 2009; 38(3):411-417. doi: 10.1590/S1516-35982009000300002.

18. Primavesi O, Godoy R, Souza FHD de. Avaliação de genótipos e recomendação de cultivares de aveia para cobertura de solo, na região Sudeste, para o ano de 2007. São Carlos: EMBRAPA. Comunicado Técnico, 2006; 66, 4p.

19. Silva JS, Queiroz AC. Análise de alimentos: métodos químicos e biológicos. 3.ed. Viçosa: UFV, 2002. $235 \mathrm{p}$.

20. Superintendência de Estudos Econômicos e Sociais da Bahia. Estatística dos municípios Baianos, 2013; 4(1):435-452. Online. Disponível em:<http://www.sei.ba.gov.br/>.

21. Tafernaberri Júnior V, Dall'Agnol M, Montardo DP, Pereira EA, Peres ER, Leão ML. Avaliação agronômica de linhagens de aveia-branca em duas regiões fisiográficas do Rio Grande do Sul. Revista Brasileira de Zootecnia, 2012; 41(1):41-51. 